\title{
THE 90th ANNIVERSARY OF THE NATIONAL ACADEMY OF SCIENCES OF UKRAINE
}

The first founding general meeting of the Ukrainian Academy of Sciences was held on November 27, 1918. Vladimir Ivanovich Vernadskii, the world-famous scientist, was appointed President of the Academy at the meeting.

It is noteworthy that a son named Boris was born in the family of Evgenii Oskarovich Paton, a professor at the Kiev Polytechnic Institute, on the very same day. Therefore, the $90^{\text {th }}$ anniversary of the Academy fell on the $90^{\text {th }}$ anniversary of Boris Paton's birth. Since 1962, he has been at the head of the highest state scientific organization of Ukraine, which was named the National Academy of Sciences of Ukraine in 1994.

More than several tens of outstanding and world-famous scientists working in various areas of knowledge were inseparably linked with the Ukrainian Academy during its existence. They are immortalized in the names of many institutes and special awards regularly given by the Presidium of the Academy for the best scientific works in relevant areas. Among these scientists are Academician Ivan Nikitovich Frantsevich, who established the Powder Metallurgy and Metal Ceramics Journal and had been its permanent editor from 1961 to 1985 and also founded the Institute for Problems of Materials Science (National Academy of Sciences of Ukraine), which is named after him, and Academician Viktor Ivanovich Trefilov, Director of the Institute from 1973 to 2001 and chief editor of the Powder Metallurgy and Metal Ceramics Journal from 1985 to 2001.

Extensive fundamental and applied research efforts are currently underway in virtually all areas of knowledge at more than 150 scientific establishments of the Academy. Nevertheless, comprehensive research and development in materials science rank high in the National Academy of Sciences. The Ukrainian Academy of Sciences is undoubtedly the world leader in this area. Materials research is conducted at institutes of not only the department of physical and technology problems of materials sciences but also the departments of mechanics, physics and astronomy, nuclear physics and energy, and chemistry. More than 10 scientific journals issued by academic establishments are completely or partially devoted to materials science. The Powder Metallurgy and Metal Ceramics Journal occupies a prominent place among them. It has been regularly issued for 48 years and provides vital information on the most recent advances in the theory and practice of powder and related technologies and information on the associated materials and parts to scientists and engineers in various areas. The subject areas of the journal are extended and replenished on a permanent basis owing to the new trend in the world science to initiate comprehensive scientific programs on the most important and promising fundamental and applied research efforts, which are also underway at the Ukrainian Academy of Sciences. A striking example is the academic program Nanosystems, Nanotechnologies, and Nanomaterials. The Institute for Problems of Materials Science greatly contributed to its development and implementation.

The National Academy of Sciences of Ukraine celebrates its $90^{\text {th }}$ anniversary in tight economic situation; nevertheless, its numerous members are not only willing to proceed with their tenacious and efficient efforts to gain new knowledge but also doing their best to overcome the economic crisis in our country.

The editorial board of the Powder Metallurgy and Metal Ceramics Journal congratulates all the readers on the occasion of the glorious anniversary of the National Academy of Sciences of Ukraine and hopes that the Academy will continue its wonderful way to Knowledge and Progress for the benefit of Ukrainian and world science. 